\title{
On Individuum and the Supraindividual in the Main Anthropological Paradigms
}

\author{
Philipp Tagirov ${ }^{1, *}$
}

\begin{abstract}
${ }^{1}$ Department of Social Philosophy, Peoples' Friendship University of Russia (RUDN), Moscow, Russia
${ }^{* *}$ Corresponding author. Email: tagirov-fv@rudn.ru
\end{abstract}

\begin{abstract}
Human is the primary question for us. It is only by answering this question that we can define the field of what we can or ought to do. The procedure we use implies formulating of the correlation between our individual self and the supraindividual. Various anthropologies propose different understanding of the supraindividual. We suggest grouping them into three main paradigms. In the first paradigm the supraindividual is dressed in clothes of mythological cosmos or metaphysical Absolute. The second paradigm considers nature in its physical meaning as the supraindividual limit our human identity is derived from. The third paradigm is called sociocentric and its supraindividual limit is society, its discoursive and institutional forms. The article studies these paradigms as main ideal types of anthropologies, the question of actual and potential limitlessness of the supraindividual limits in anthropological paradigms and the problem of the coexistence of different paradigms.
\end{abstract}

Keywords: absolute, anthropology, cosmos, human, identity, individual, nature, man, society, supraindividual

\section{INTRODUCTION}

Often, when we touch upon the question of the essential characterization of human, the category of consciousness is proposed as a solution. Another answer is the idea of rationality, included in the very name of the human species: Homo sapiens. However, is consciousness a specifically human trait? In a certain sense, consciousness is the ability to be aware of objects of the habitat and of some connections that exist in it and, relating oneself to the reality of the surrounding world, "resist the spontaneity" of one's existence, in the words of M. Scheler [1] But in this sense consciousness is inherent in many other living things. If we separate man from other animals because of his rationality, as Aristotle, who called man an animal rationale, did, then let us ask ourselves after E. Cassirer [2]: yes, let's say rationality is a feature inherent exclusively in man, but is the man himself exclusively rational? Do we sometimes reason (and even more often than we are ready to admit) completely illogically, do we not make decisions and do not commit acts despite all the rational arguments?

In his thinking, however, a human being has the ability to think about how he thinks, and in his speech to speak about how he speaks, that is, to take his own thinking and speech acts as a subject of reflection and speculation. Therefore, we can assert this or that identity, say "I am this" or "we are that," but due to the

${ }^{*}$ The publication has been prepared with the support of the RUDN University Program 5-100. dynamism of the symbolic substrate of our language, we can not only state our own identity, but also question it ("is this really me?", "are we really that?"), and reassert it in a new way. Thus, we come to the perspective of the self-consciousness, which seems to be the distinguishing characteristic of a human.

Self-consciousness implies looking at oneself, but at the same time it is necessarily means the detachment from oneself, going beyond the boundaries of oneself as the subject of our knowledge. It is how H. Plesner [3] saw the specifics of human eccentricity - the ineradicable distancing of the center of our positionality from itself.

What is self-knowledge? First of all, it is an activity aimed at defining oneself, that is, at finding one's own limits. Defining ourselves, we draw a circle within which we actually are, and beyond which is what we are not. But what allows us to delineate this "magic" circle that protects us from any demons who, otherwise, would tear to pieces, disembody our identity? And why does this circle sometimes appear so different for different people and cultures? The fact is that in delineating ourselves, our individual (in-dividuum), atomic ( $\ddot{\alpha}-\tau \circ \mu \circ \varsigma)$ self, which can be divided no more, we start from our ideas about something that surpasses us many times (or even infinitely), something superior, which makes us just that, and not any other thing. Thus, we could conclude that we highlight our individual limits through correlation with the supraindividual and that we find ourselves in comparison with our supraindividual. However, it would be more correct to 
say that we are not just this individual, but our very correlation between the individual and the supraindividual.

This correlation of the individual and the supraindividual can have different forms of expression. However, we can speak about certain "metaforms", archetypes, which lie at the basis of various correlations that form our "I" and our "we", correlations that often are quite dissimilar at a phenomenal level, but related in their essence. Such "metaforms" are paradigmatic and make it possible to combine various anthropologies on the principle of not external similarities or even historical continuity, but internal relatedness - not necessarily genetic, but semantic one. Thus, we can speak about the main anthropological paradigms and try to highlight their "coordinate systems".

At the same time, we should note the ideally-typical nature of paradigms: they are presented to us as ideal models and structures of speculation, by which a person defines himself, but not as concrete speculation as such. However, concrete speculation tends to these models and is carried out within their boundaries and according to their laws. And it is according to the degree of compliance of a speculation with these boundaries and laws, we can attribute it to one or another anthropological paradigm.

Based on the understanding of man's supraindividual limit and their correlation ("quid hoc ad aeternitatem", "quid aeternitas ad hominem"), we can identify three main anthropological paradigms which are mytho-metaphysical, physically natural and sociocentric ones. In the first case, the cosmos or the metaphysical Absolute, with which man correlates by means of the spirit, seems to be the supraindividual limit. In the second paradigm it is nature, freed from its mythological or idealistic understandings (or: deprived of them), with which a person correlates, first of all, thanks to his body and in accordance with the possibilities that this body gives us and within the limits it puts. And, finally, in the third paradigm, this supraindividual limit is thought to be the social, and the key intermediary between the individual and the supraindividual is the meaning, which is historical, sociogenic, and culturally conditioned.

\section{COSMOS AND THE ABSOLUTE AS}

\section{SUPRAINDIVIDUAL LIMITS OF THE MYTHO-} METAPHYSICAL ANTHROPOLOGICAL PARADIGM

The mytho-metaphysical anthropological paradigm has its roots in the deepest ancientry, almost in the very dawn of humanity. Can we also call this paradigm religious? Yes and no.

No - with a sociological understanding of religion, first of all, as a social institution, with its cult-ritual component, sacred canons, and distinct class of people attached to special knowledge and performing a mediating function between man and the highest reality, etc. The myth may be considered as a system of views upon the world, built on sensual images, while the metaphysical system is based on theoretical concepts. Religion can include both myth and metaphysics (doctrine). However, we are well aware of another concept of religion, where it is fundamentally distinguished from the myth and even contrasted with it - and we will find supporters of this approach among the clergy theologists and among scientific theorists.

However, our answer will be positive if we comply to a broader understanding of religion, according to which religious experience, experience of the sacred or numinous experience, using Rudolph Otto's concept, can also be available to a person who is outside the body of a certain institutionalized religion. There cannot be religion of a single person, but the religiosity of an individual is possible (another question is how genuine it may seem from the point of view of a particular religion). Does this ability to have "religiosity before or outside religion" dwell in the very nature of the human being, in the longing of a finite being for the being infinite, or in some kind of premonition, insight? Is the myth just one of the forms of the description of reality or is it, as C. Levi-Strauss believed [4], a level of language that determines the thinking of the subject? In the latter case, the myth as a language will underlie the metaphysical reasoning and metaphysical doctrine. We can also imagine the opposite picture, according to which metaphysical doctrine reveals itself to the highest metaphysical truth [5], which is divine, through the intellectual intuition, and the myth turns out to be a more external level of its manifestation, where the intellect gives way to other cognitive abilities of man.

Cosmos as a supraindividual limit, as a rule, is inherent in the polytheistic worldview, which by the representatives of monotheistic religions, addressing the metaphysical Absolute, is also called "pagan". Nevertheless, when comparing developed models of polytheism, which, for example, Jan Assman defines as "complex polytheism" and where various divine instances represent different hypostases of the divine as such [6], with, say, Christian monotheism (with its cult of not only the Trinity, but also The Virgin Mary, and with its institution of patron saints), in spite of doctrinal differences, we, with the necessary provizo, can admit a certain structural and functional similarity between them.

Does the distinction between the cosmos and the metaphysical Absolute, as well as two very different views on the world and the two different ways of relating oneself with a supraindividual limit, emphasize two paradigms instead of one? This argument, of course, has a sense, however, in spite of all differences, these two models are united by the conviction in the 
presence and primacy of a certain reality (if visible, then only in its manifestations), which lies at the basis of both physical and social order. And this fact radically distinguishes these models from the second and third paradigms.

The variety of actual anthropologies that seem to be included in the first paradigm raises another question: can the category of "spirit", "spiritual" be considered as a general concept, encompassing the means by which the individual being in the mytho-metaphysical paradigm is linked to the supra-individual? The question is ambiguous. Did not the immersion of an archaic person in the world around him dissolve him in the elementally-natural, even if revealed by means of mythological images that personified one or another of its manifestations? If so, then where in this elementally nature is a place for the spirit?

In the context of the Abrahamic creationist models, material nature appears as a creation of the divine principle, and human life is centered around its connection with the universal metaphysical source, which is possible due to the fact that the person is not only the body and the dimensions of mental and social processes associated with its physical existence, but also the bearer of spiritual components, including those unconditioned by the external circumstances of his existence. The path of a true believer demands his full devotion, his life becomes the mission of serving the God in a way his religion prescribes. It varies from Judaism [7] to Islam [8], from catholic to protestant [9] Christianity but the only mean to completely fulfill one's destiny given from above is to follow this mission.

The nature with which the non-Abrahamic man of the first paradigm (who is, according to M. Eliade, no less than the man of the monotheistic creationist religions, belongs to the type of homo religiosus and whose existence is "open" to the cosmos [10]) correlates himself, is not something "natural" in the modern sense, but, on the contrary, always, in all its manifestations - living, animated, existing in the tact with the timeless logic of the spiritual order. However, it should be noted that for the person in question, this is the natural order of things, so we can say that it is natural for this nature to be "supernatural."

It is not without reason that the state of "openness to the world" itself is conceived not as given from birth, but as what should be achieved through training, initiation, the second birth, which, according to the initiatory model, is presented as a spiritual birth that introduces the subject to the world's logos, giving a person his real form as a human microcosm and making possible his meaningful inclusion in the rhythms and logic of the macrocosm.

\section{NATURE AS THE SUPRAINDIVIDUAL LIMIT OF THE SECOND PARADIGM}

The essential boundaries and main guidelines of the second anthropological paradigm, the foundations of which are laid back in the Modern Time (and in some ways go back to anticlericalism and freethinking of the Renaissance), are well outlined, though not exhausted, by the key ideas of the school of philosophical anthropology, primarily represented by M. Scheler (minus his metaphysical reasoning) [11], H. Plesner [3] and A. Gehlen [12].

The evolving of man from the natural world is the main anthropological idea of this paradigm. Nature is conceived herein as animate and inanimate, and the difference between the former and the latter is the life's ability of "expressing" itself (M. Scheller) or its propositionality (H. Plesner). The inanimate body transits into the environment, while the living carries its limits within itself and expresses itself to the outside. The plant has an open form and is incorporated into the environment, its positionality is strictly limited, the animal has a closed form, which allows it to achieve the openness of its positional field. Center of animal positioning is distanced from the body and correlated both with it and with the environment. An animal can arbitrarily change its place in the surrounding world, but always resides in its here-and-now. A human exists, first of all, not in the surrounding world, but in the world as a speculative construction, therefore, being in any particular situation, he simultaneously remains "out of place" and "out of time". His center of positionality is distanced from itself, which allows him to take himself as a subject of his own questioning. Man is not the crown of creation, the life force decreases from plant to animal and further from animal to human. But where the life diminishes, as M. Scheler believes, the spirit grows.

This paradigm triumphed after the "death of God", diagnosed by F. Nietzsche, and the spread of materialism, positivism and pragmatism, as well as agnosticism or nihilism in appliance to the "higher world" truths and values due to their metaphysical nature, which puts them outside the boundaries of the new paradigm of knowledge. The existence of metaphysical reality (including the divine) in the physically natural paradigm is either denied, or recognized as unprovable and incontrovertible at the same time (antinomies of pure reason as synthetic a priori judgments by I. Kant), or allowed, but along with the assurance of the lack of value of such knowledge for practical life of people (for example, in certain forms of deism - in J.-J. Rousseau's or Voltaire's ones).

Nietzsche's statement "God is dead" [13] is not a cry of a heretic or an atheist, but a statement of a certain cultural and historical situation. A society that for centuries existed with a constant eye on God, began to 
limit its horizon primarily to the material and natural phenomena, and people's interests and their legitimation were reduced to a purely earthly logic. This does not mean that there are no believers left, but how many of them, having left the church after the service ended, do not begin to behave as if there was not God? The situation of recognizing the "death of God" requires building a new anthropology - the anthropology of nihilism, which is closely connected in Nietzsche with the figure of the Übermensch and the recognition of the need for constant revaluation of values in accordance with the will, which is the driving force of all living things, - the will to power. Old values lose their motive force, because a man no longer has the authority above, on whose behalf they are established and who can judge a man for all he's done. New values will certainly be created, this time on behalf of the man himself, but what will they be? A man could allow himself to be weak in the presence of a severe Father, whose external presence, imaginary or real, encouraged the man to overcome himself and not descend to indulging his own weaknesses. But after "God is dead," who can guide a man to the path of self-overcoming? It is only the man himself, but for managing this, he must be transformed, must overcome what is "human, too human" in himself, to become what Nietzsche calls "Übermensch", whose will to power, before turning to other people and the world around, is directed at himself. At the same time, "the death of God" can lead to passive nihilism, when new values turn out to be the values of the "last man", values of self-indulgence.

As in the case of the mytho-metaphysical paradigm, the second anthropological paradigm is heterogeneous. In particular, the specific place in it is occupied by the anthropology of existentialism. (It is worth here, perhaps, to put out of brackets its religious devision, which, like the idea of the "becoming God" by M. Scheler seems to be an attempt to choose a new language to express some of the core elements of the previous paradigm in a language that could make them "up to date"). What allows us to include existentialist anthropology in this paradigm? This is, again, nature as a supraindividual limit, which, however, is viewed by existentialism, negatively, as rejecting man, and thereby denying him any external support, with the result that man is doomed to courageously admit the "uncoveredness" of his being (O.F. Bollnow [14]). This is the first step towards seeking support in what remains, even if everything is lost, - in our authentic existence.

\section{THE SOCIOCENTRIC PARADIGM AND THE SOCIAL AS ITS SUPRAINDIVIDUAL LIMIT}

The third paradigm proposes the social as the supraindividual limit for a man. How did nature disappear? Like the "death of God", and with it the departure of the world of the suprasensual [15] in process of the "overcoming of metaphysics", in the third paradigm it is the "natural" that is being overcome. How is this possible if man comes from nature and dwells in it? A society, once emerged from the natural world, over time gains greater autonomy, and also develops the ability to interfere in nature and even in the nature of man himself according to the meanings or discursive tensions that dominate the historical moment.

The post-non-classical scientific rationality, as defined by V.S. Stepin [16], also applies to the sociocentric paradigm. In this rationality cultural and value components are recognized as unavoidable from the activity of the knowing subject. The subject of knowledge is no longer an observer, but a participant in the events taking place. Man is a factor whose impact on reality cannot be ignored. The cultural value orientations of individuals predetermine their transformative and cognitive activity. Knowledge itself is no longer value-neutral.

The plasticity of human nature here is thought as being dependent not so much on natural causes as on social dispositions. In this, the idea expressed, in particular, by $\mathrm{H}$. Plesner, that it is natural for man to be artificial, becomes even more actual.

Social criticism has its certain incarnations in the first two paradigms but it is here where it ascends to the principally new height and gets its full embodiment [17]. In the frames of mytho-metaphysical anthropological paradigm the "critical" sting is aimed at moral vices and religious bankruptcy or heresies of individuals, groups and societies - in other words, it bites what fails to properly correspond or even contradicts the prescriptions that were believed to come from the truth above or from supernatural order of things. The physically natural paradigm strips the criticism of clothes of this kind and tears this sort of foundation out of it. It seems that it almost becomes purely social criticism, but we should not neglect its possible linking to the natural soil where the discourse of this paradigm is rooted. Nature provides this discourse with the horizon of personal and social development and the means for it. In some theories like biological racism or social Darwinism nature is also believed to determine the principal difference among people and superiority of the certain races, classes or sex and the inferiority of others.

The sociocentric paradigm completely turns us to ourselves and other people and social mechanisms that link us together even against our will and disregarding us knowing it or not. And the social criticism in this paradigm enriches us with its new forms and methods unknown in the former paradigms. It exposes our societies as authoritarian [18], repressive [19], onedimensional [20] or disciplinary [21]. It attacks the 
flaws of mass society or prosumer society [22]. It troubles us with gender inequality and coerciveness [23] and proposes the ways of undoing gender [24]. It goes to the deconstruction of our social practices and even to the deconstruction of our knowledge [25] and the mere concept of us and so bringing us anthropological freedom and, at the same time, uncertainty...

The change of anthropological paradigms, of course, is influenced by external factors, such as geographical discoveries, technological progress, changes in communicative practices, etc., but, on the other hand, our ideas about ourselves, our capabilities and tasks largely determine our practices. As many authors noted, in particular, C. Schmitt [26], Europeans sailed to America long before the era of great geographical discoveries, but it was Columbus who really discovered it, because of the changed ideas about reality, in which, among other things, the category of infinity was transferred from the metaphysical Absolute to the natural world, allowing to take a fresh look at the supraindividual limits of man, which resulted in the desire to search, discover and colonize new lands on the other side of the seemingly boundless ocean.

\section{ACTUAL AND POTENTIAL LIMITLESSNESS OF THE SUPRAINDIVIDUAL LIMITS IN ANTHROPOLOGICAL PARADIGMS}

The supraindividual limit, with which the individual correlates in one or another anthropological paradigm, serves not only as the Other, in comparison which we define our "I" and "we". Primarily it represents the ultimate limits of the expansion of our finite being. At the same time, the supraindividual limit gives an answer to the question about the potential possibility of the limitlessness of our being in accordance with the logic of the paradigm we belong.

The mytho-metaphysical paradigm, where the supraindividual limit is cosmos and the pre-cosmic principle (for example, the unmanifested Tao) or the metaphysical Absolute (for example, God of monotheistic religions), proposes the idea of the actual limitlessness of the supraindividual limit. In some cases (as, say, in the Hindu tradition, in Neo-Platonism or in Meister Eckhart), finite human existence implies the possibility of overcoming a limited and conditioned existence and achieving actual infinity in the One or the Absolute ("Atma is Brahman").

The supraindividual limit of the physically natural paradigm has an actual-potential limitlessness. For Giordano Bruno, the infinity of the world, for example, served as the basis for optimism associated with believing in the possibly infinite development of man in a world that has no limits. However, according to the logic of this paradigm, in the actually infinite natural world, human existence is only potentially limitless, since it is actually limited by human mortality and the individual boundaries of his natural capabilities.

Hope for future expansion, and ideally the elimination, of the boundaries imposed on humans by nature, inspires, in particular, by the representatives of transhumanism, which, however, should rather be attributed to the third paradigm, because it thinks of nature as something that can be transformed by joint efforts of developing scientific knowledge and technical intervention - that is, by sociogenic factors.

Sociocentric anthropological paradigm, as already mentioned, considers the social as a supraindividual limit for human existence. In this case, the limitlessness of both human existence and the social space is only potential. Constructivist models, that seem to express the essence of the sociocentric paradigm, suggest high plasticity of both social reality and human nature. Potentially, a society can be very different (for example, patriarchal, matriarchal, or biarchal), however, we note that any actual society exists in concrete, definite (that is, finite) institutional forms, and even if it changes radically, it is always a change from one finite concreteness to another. A man in society can also choose between various projects of social realization, but only within the limits, that depend on the type of society, its openness (according to $\mathrm{K}$. Popper [27]), the degree of social mobility, etc., and at the same time each choice cuts off some of the other, previously potentially available to him, opportunities.

\section{CONCLUSION}

We have to admit that many authors cannot be clearly attributed to one or another paradigm, because in some arguments they can be closer, for example, to a physically natural paradigm, while in other arguments to a sociocentric one. This is not a problem for us, because this study concernes not the personalities themselves, but the ideas that these authors have expressed.

It is important to emphasize that the approval of a new paradigm means, first of all, its dominance, but not a complete replacement of the preceding paradigm.

Centuries after the adoption of Christianity by Constantine and the banning of pagan cults by Theodosius, the "Christianized" territories preserve the pagan world perception, as a rule, in various forms of hidden polytheism. According to $M$. Eliade and a number of other authors, for example, a very distant from the canonical Christian attitude to nature and the cosmos as something living and full of spirit, or not familiar to present day people linear but cyclic experience of time was fairly typical on to the Eastern European peasant of the first half of the XXth century. A. de Benois [28] and D. Venner [29] even claim that 
the paganism has never died at all and continues to live through, behind or parallelly to both the Christian culture phenomena and modern secular social forms. Similarly, in spite of the dominance of the second anthropological paradigm, scientifically based views in the minds of a significant number of people are combined (often in an eclectic and unreflected manner) with those or other beliefs rooted in mythometaphysical paradigm.

Thus, it can be claimed that the first paradigm does not disappear completely, does not depart into the past, but ceases to be a legitimate basis for the dominant epistemological, sociopolitical, and, first of all, anthropological discourses. Likewise, the spread of the third, sociocentric, paradigm is accompanied by the preservation of models rooted in previous two paradigms.

On the one hand, it is possible to talk about the possibility of choosing a paradigm, which a person of the past was deprived of, but on the other hand, one cannot avoid the question of how free a person really is in this choice.

As a result, we find ourselves in an anthropological situation, characterized by numerous contradictions associated, for example, with the difficulties caused by the legacy of the first, mytho-metaphysical, paradigm while trying to consistently follow the principles of the second and third paradigms. The efforts of the third, sociocentric paradigm, aimed at overcoming dependence on the principles of the physically natural paradigm, cannot always be crowned with success. And finally, no less problematic and sometimes even painful is the question of the man's possibility of full and fruitful incorporation into the models of the first paradigm in the situation of dominance of the second and third paradigms.

In addition, another question also arises: isn't the sociocentric paradigm already obsolete? In the age of cyber technology, artificial intelligence, object-oriented philosophy [30] and non-anthropocentric ontology, aren't we moving towards anthropology without anthropos? However, this would no longer be anthropology, and in this case, we can hardly speak of a transition to a new, the fourth anthropological paradigm, although the sociocentric paradigm, of course, is changing and thus shows its potential diversity. Studying, for example, the issue of whether a robot can have self-consciousness or even a soul, a person ultimately asks not about being a robot, but about his own being: what is there to be a creator? What are my possibilities and boundaries as a creator? And finally, what is this soul, and do I have one? As before man remains the main problem for himself, and he is trying to solve it on the basis of those guidelines that this or that anthropological paradigm offers him - the key point is what paradigm exactly he feels belonging to.

The search for answers that could contribute to the resolution of these difficulties and contradictions cannot be accomplished by any anthropology in a way that would satisfy the other ones, since any of them proceeds from the paradigm to which it belongs. A prerequisite for such a search is to reach a certain metaparadigmal level. Is this condition possible? For now the question is open

\section{References}

[1] M. Scheler, The Human Place in the Cosmos. Evanston: Northwestern University Press, 2009.

[2] E. Cassirer, An Essay on Man: An Introduction to a Philosophy of Human Culture, New Haven, Connecticut, Yale University Press, 1944, chapter 2.

[3] H. Plessner, Levels of Organic Life and the Human: An Introduction to Philosophical Anthropology (Forms of Living). 1st Edition. Fordham University Press, 2019.

[4] C. Levi-Strauss, Structural Anthropology. Basic Books, Inc., Publishers, New York, 1963, pp. 206-231.

[5] R. Guenon, Introduction to the Study of the Hindu Doctrines. London, Luzac\&Co, 1945, pp. 87-176.

[6] J. Assman, Ägypten: Theologie und Frömmigkeit einer frühen Hochkultur, Stuttgart 1984

[7] D. Cohn-Sherbok, Judaism: History, Belief and Practice. Routledge, London and New York, 2003, pp. 404-460, 533 538.

[8] F. Rahman, Major Themes of the Qur'an: Second Edition. University of Chicago Press, 2009, pp. 17-64.

[9] M. Valco, "The roots and nature of luther's theological understanding of 'missio dei' in the context of his reformation agenda" in European Journal of Science and Theology, August 2016, Vol.12, No.4, 181-188

[10] M. Eliade, The Sacred and The Profane. The Nature of Religion. A Harvest Book, Harcourt, Brace \& World, Inc., New York, 1963, chapter 4.

[11] M. Scheler, M. Scheler, The Human Place in the Cosmos.

[12] A. Gehlen, Man. His Nature and Place in the World. Columbia University Press, 1988.

[13] F. Nietzsche: The Gay Science: With a Prelude in German Rhymes and an Appendix of Songs. Cambridge University Press, 2001, § 125 .

[14] O.F. Bollnow, Neue Geborgenheit. Das Problem einer Überwindung des Existentialismus. Stuttgart, 1960.

[15] M. Heidegger, 'Nietzsche's Word: "God is Dead"' in M. Heidegger, Off the Beaten Track. Cambridge University Press, 2002, pp. 157-199.

[16] V. Stepin, "Classics, non-classics, post-non-classics: criteria of distinguishing" in Post-non-classics: philosophy, science, culture. SPb, Mir, 2009, pp. 249-295 (in Russian).

[17] S. Rudanovskaya, "Social Criticism: From Utopia to Postutopian Thought" in Proceedings of the 2nd International Conference on Contemporary Education, Social Sciences and Humanities (ICCESSH 2017). Paris, Atlantis Press, 2017, pp. 69-73. doi:10.2991/iccessh-17.2017.16

[18] Reich W. The Sexual Revolution. Farrar, Straus and Giroux, New York, 1974

[19] H. Marcuse, Eros and Civilization. Beacon Paperback, 1974 
[20] H. Marcuse, One-Dimensional Man. Routledge Classics, London and New York, 2002,

[21] M. Foulcault, Discipline \& Punish: The Birth of the Prison. Vintage Book, 1995.

[22] J. Bauldrilliard, The Consumer Society: Myths and Structures. First edition. SAGE Publications Ltd, 1998.

[23] J. Butler, Gender trouble: feminism and the subversion of identity. New York, 1990.

[24] J. Butler, Undoing Gender. New York , 2004.

[25] J. Derrida, Of Grammatology. Johns Hopkins University Press, 1998.

[26] C. Schmitt, Land and Sea. A story for my daughter Telos Press Publishing, 2015.

[27] K. Popper The Open Society and Its Enemies. 1st edition. Routledge, 2012.

[28] A. de Benoist. On Being a Pagan. Atlanta, Ultra, 2005.

[29] D. Venner, Histoire et tradition des Européens: 30000 ans d'identité. Editions du Rocher, 2011.

[30] G. Harman, Object-Oriented Ontology: A New Theory of Everything. Pelican, 2018. 